\title{
Impact of Clinical Pharmacist Counselling and Education on Quality of Life in Patients with Acute Coronary Syndrome
}

\author{
Uday Venkat Mateti ${ }^{1 *}$, Jasmine Ummer ${ }^{1}$, Subramanyam Kodangala ${ }^{2}$ \\ ${ }^{1}$ Department of Pharmacy Practice, NGSM Institute of Pharmaceutical Sciences, Nitte University, Deralakatte -575 018, MANGALORE. \\ ${ }^{2}$ Department of Cardiology, K.S. Hegde Medical Academy, Justice K.S. Hegde Charitable Hospital, Nitte University, Deralakatte, \\ MANGALORE.
}

\begin{abstract}
Objectives: To assess the impact of clinical pharmacist counselling and education on Quality of Life (QoL) of patients with acute coronary syndrome (ACS). Methodology: A prospective interventional study was conducted for a period of 8 months. The ACS patients were categorized into intervention and control groups by randomization process. The intervention group was given patient counselling and patient information leaflets along with the usual care while the control group received only the usual care. The patient counselling, education and leaflets were provided only at the end of the study to the control group. The QoL of patients was assessed by WHOQOL-BREF questionnaire at baseline, third month and sixth month of the study. The change in QoL scores between the two groups over a period was analysed by Repeated Measures of ANOVA with $p$ value less than 0.05 was considered as statistically significant. Results: A total number of 130 patients ( 65 patients in the intervention group and 65 in the control group) were enrolled in the study. The mean age for the intervention group was $60.23 \pm 10.07$ years and for control group was $57.85 \pm 10.67$ years. There is no significant difference in the QoL scores of Physical, Psychological, Social Relationships and Environment domains between the two groups with $p$ value more than 0.05. Conclusion: There was no statistically significant change in QoL scores of the ACS patients. However, there is an improvement in the QoL scores of the intervention group to that of the control group.
\end{abstract}

Key words: Pharmacist Counselling, Patient Education, Patient Information Leaflet, Interventional study, Quality of Life.

\section{INTRODUCTION}

Acute Coronary Syndrome (ACS) refers to "a group of conditions compatible with acute myocardial ischemia and/or infarction that are usually due to an abrupt reduction in coronary blood flow". ${ }^{1}$ It is the major cause of morbidity and mortality around the world. In India, ACS is the main reason of death causing one third of all deaths in the country. World Health Organization (WHO) and Indian Council of Medical Research (ICMR) proclaim that India will be the heart attack capital by the end of 2020 along with other diseases. This is an alarming rate and a big threat to the nation. ${ }^{2}$
The treatment should be started as early as possible after the occurrence of an ACS event and patient should be rushed to the hospital during the onset of a heart attack. However, in spite of the intense pain associated with ACS, people delay taking hospital treatment due to their lack of information and knowledge about ACS. Researches have proved that education of patients improves their response to the disease and its management and their QoL. ${ }^{3}$ In addition, the result of the treatments done can be analysed from this. ${ }^{4}$
Submission Date : 28-03-2016 Revision Date : 12-05-2016 Accepted Date :13-05-2016

DOI: 10.5530/ijper.50.3.7 Correspondence: Dr. Uday Venkat Mateti, Pharm D, Ph.D. Asst. Professor, Dept. of Pharmacy Practice, NGSM Institute of Pharmaceutical Sciences, Nitte University, Deralakatte 575 018, Mangalore. Email id: udayvenkatmateti@gmail.com

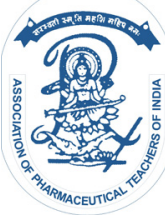

www.ijper.org 
The understanding of the factors affecting QoL is very beneficial to improve QoL of the patient. Researchers have been proved that certain diseases were not properly cured due to the poor understanding of the patients about the disease. So this intervention will be very beneficial. ${ }^{5,6}$ Hence, patient education and patient counselling is very important in the treatment regimen for eradicating ignorance and to impart good QoL. This should be given from the time of hospital admission of the patient.

QoL outcomes help reducing morbidity and mortality rate in the patients. This helps to eradicate the health hazards in the patient's daily life. The sooner the intervention is done, the better is the result obtained. Many methods are recommended to improve the care given to the patient at discharge, but they have not yet been put into action. In addition, the rehabilitation programmes helps in the functional betterment and Quality of Life (QoL) betterment in case of an ACS patient. ${ }^{7}$ This study will be very helpful as there is lack of proper counselling and education after ACS in the current scenario.

\section{Methodology}

\section{Study Design, Site and Ethical Approval}

A prospective interventional study was conducted in the Cardiology Department at Justice K S Hegde Charitable Hospital, Mangalore for a study duration of 8 months (June 2015 to Feb 2016). Prior to the initiation of the study, ethical approval was obtained from central ethical committee (REF NO: NU /CEC/ P.G -09/2015), Nitte University, Mangalore.

\section{Study Criteria}

All ACS patients of either gender of above 18 years of age admitted in the hospital during the study period were included in the study. While pregnant, lactating and mentally challenged patients, patients admitted in intensive care unit and patients who cannot communicate in English, Malayalam and Kannada languages were excluded from the study.

\section{Development, Validation and Readability Testing of PILs}

\section{Development of PILs}

The PIL was developed in English language based on the various primary, secondary and tertiary resources. The primary resources such as various articles based on ACS, its prevention and management; secondary resources such as websites like Micromedex, Medscape, Patient.info, Mayoclinic, Drugs.com, etc and tertiary resources such as textbooks like Pharmacotherapy,
Clinical Pharmacy and Therapeutics and guidelines from Scottish Intercollegiate guidelines, Ireland's Health Service Executives, Egton Medical Information Systems of primary care in England, National Health Services in England were referred to prepare the PILs. The content of the PIL included information on ACS, its types, symptoms, causative factors, risk factors, diagnosis methods, treatments and management criteria's.

\section{Validation of PILs}

The expert validation process was carried out by doctors $(\mathrm{n}=5)$, academic pharmacists $(\mathrm{n}=3)$, post graduate doctors $(n=2)$, nurses $(n=3)$ and technician of the cardiology department $(\mathrm{n}=1)$. The validation was done by using criteria checklist for evaluation of tool. They were asked for necessary opinions and suggestions in the model submitted to them. After making the necessary changes as per the expert guidance the PIL was made and then checked for readability.

\section{Readability of PIL}

The readability scores were obtained using the Microsoft Office Word 2010 application and the scores were calculated based on the various tests as:

Flesch Reading Ease Test: Where the scoring is done out of 100 scales, the easier to read and understand the document and the range for a standard readable document is $60-70$.

Flesch- Kincaid Grade Level Test: Where the scoring is done based on the U.S School Grade Level of understanding. The standard level of understanding is between the grade levels of 7.0 to 8.0.

\section{Designing of PILs}

Baker Able Leaflet Design (BALD) Criteria was used to determine the layout and design of the PIL. The scores are calculated based on length of the line, distance between the lines, letter font size, graphics used, per cent of white space, paper quality etc. A score of 25 and above is considered standard and of good layout and design. This ensures that the patients are very well able to read the PIL and that the presentation of the PIL is very standard.

\section{Translation of PILs}

Professional translators carried out the translation of the validated PILs into the Malayalam and Kannada languages using translation steps like forward translation, backward translation and patient testing. 
Methodology for Impact of Patient Counselling and Patient Education on QoL of ACS Patients

\section{Randomization process}

The process of randomization was done by chit method and the groups were randomly assigned into intervention and control groups in 1:1 ratio. The sample size required for the study was calculated using following equation for "repeated measurements in continuous data".

The equation is,

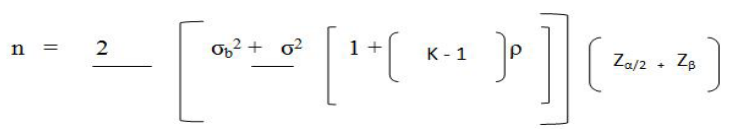

$\sigma_{\mathrm{b}}^{2}$ - between group variance

$\sigma^{2}$ - within group variance

$\rho$ - intra class correlation coefficient

$\delta$ - effect size

$\kappa \quad$ - number of repeated measures

$\alpha$ - significance level

$1-\beta$ - power

If variance is 2,3 within group variance is 2 , between group variance is 3 , intra class correlation is 0.5 , number of measurements 3 , effect size is $0.8,80 \%$ power, level of significance $5 \%$ and hence required sample size is 106. If anticipated dropouts is $15 \%(n=16)$, then sample size is 122 (approx. 130).

\section{Control group}

The control group received the usual care provided by the doctors, nurses and technicians. The patient counselling, education and PILs were provided to this group at the end of the study.

\section{Intervention group}

The intervention group provided patient counselling and PILs along with usual care group. The counselling program includes the information about the disease, treatment goals, and importance of medication adherence, possible adverse drug reactions, management of the disease and life style modifications.

After the baseline assessment, the intervention group was given tailored counselling based on initial assessment with usual care. At the $3^{\text {rd }}$ month or $2^{\text {nd }}$ follow-up the intervention group was given PILs along with counselling and usual care, and it was continued till the end of the study.

\section{Instruments}

The QoL outcome of the ACS patients was evaluated using a pre-validated World Health Organization Quality Of Life (WHOQOL) questionnaire with 26 questions.
The physical, social, psychological and environmental domains were considered in the WHOQOL questionnaire.

\section{Data collection process}

A data collection form was made including patients' demographics, social habits, family history, past medical and medication history, co-morbidities and symptoms of the patients. After obtaining the informed consent form from the patients, the data was collected.

\section{Outcome assessment}

The QoL for the both groups were evaluated at baseline, third month and sixth month. A flow-chart using consort flow chart model was created pictorially in Figure 1 to provide a visual representation of the entire process.

\section{Statistical analysis}

The change in QoL scores between the two groups over a period was analysed by repeated measures of ANOVA with $p$ value less than 0.05 was considered as statistically significant. Data was analysed by using the software statistical package for social sciences (SPSS) software version 16.0

\section{RESULTS}

\section{Patient Information Leaflets}

A PIL was prepared for the study and the readability scores were obtained after validation and designing of PIL. The readability scores of the PIL for Flesch reading ease test scores was 64 and Flesch-Kincaid grade level test score was 7.3. The readability scores indicates that the prepared and validated PIL was plain English and can be easily understood even by $8^{\text {th }}$ and $9^{\text {th }}$ grade school level education. The design and layout of the PILs was assessed using BALD criteria and the scores were 25 for English and Malayalam and 26 for Kannada PILs.

\section{Baseline Demographic Details of the ACS}

Out of 130 patients, 65 patients were in the interventional group and 65 patients were in the control group. A total number of 20 patients lost the follow-up during the study period. The majority of the ACS patients were in the age group between 51-60 years of age [20 (30.8\%)] in control group and $61-70$ years of age [25(38.5\%)] in intervention group. The age wise distributions of ACS patients in other age groups are summarized in the Table 1. The mean age of the patients was $60.23 \pm 10.07$ and $57.85 \pm 10.67$ years for intervention and control groups respectively with $\mathrm{p}$ value of 0.081 . In the both groups male patients [38(58.5\%) and 45(69.2\%) for control and intervention groups respectively] outnumbered the female patients [27(41.5\%) and 20(30.8\%) for control 
and intervention groups respectively]. There is no gender wise difference in the both groups with $\mathrm{p}$ value of 0.273 . In the both groups the predominance of hypertension [40(61.5\%) and $33(50.8 \%)$ for control and intervention groups respectively] was more followed by diabetes mellitus [13(20\%) and 25(38.5) for control and intervention groups respectively] and other diseases [9(13.8\%) and $8(12.3 \%)$ for control and intervention groups respectively]. The differences between the two groups were analyzed by Chi-square test and Fischer's exact test. The detailed results of co-morbidities associated with ACS patients are summarized in the Table 1.

It was observed that there were 10(15.4\%) alcoholics in the intervention group and $4(6.2 \%)$ in the control group. The smoking rate was higher in the intervention group with $14(21.5 \%)$ whereas $10(15.4 \%)$ in control group. The data was analyzed by using Fischer's exact test (p 0.374) and Chi-square test (p 0.155) respectively for the alcoholic and smoking patients. In the present study, most of the patients had no family history of ACS. The mean number of drugs per prescription was $6.123 \pm 2.46$ and $6.123 \pm 2.32$ for the control and intervention groups with $p$ value 0.693 by Chi-Square test. The other demographic details are summarized in the Table 1.

\section{Symptoms of ACS Patients}

In present study, chest pain was the major symptom observed in both control group 52(80\%) and intervention group $53(81.5 \%)$ followed by dyspnea on exertion was $26(40 \%)$ in control group and $27(41.5 \%)$ in intervention group. The symptoms experienced by the patients are summarized in the Table 2.

\section{Baseline QOL scores}

The QoL scores were presented as Mean \pm SD for all the four domains (Physical, Psychological, Social Relationships and Environment) for the control group and the intervention group. The difference in the baseline QoL scores of the two groups were analyzed by independent sample test. Except social domain the other three domains were not significantly differed with $\mathrm{p}$ value more than 0.05. The detailed baseline QoL scores are summarized in the Table 3.

\section{Impact of Patient Education and Patient Counseling on QoL of ACS patients}

There is no significant difference in the QoL scores of Physical, Psychological, Social Relationships and Environment domains between the two groups with $\mathrm{p}$ value more than 0.05 . The domain $\mathrm{p}$ values were found to be 0.961 for Physical domain, 0.433 for Psychological domain, 0.364 for Social Relationships domain and 0.354 for Environment domain respectively indicating that there is no statistically significant difference in the QoL scores of ACS patients in both the groups over a period. The QoL domain scores of both the control and the intervention groups are summarized in the Table 4. The change in the QoL scores from baseline to last follow-up for the intervention and control groups for the domains Physical (8.24 \& 8), Psychological (5.61 \& 4.11), Social Relationships ( $2.81 \& 1.46)$ and Environment $(1.74 \& 1.04)$ respectively.

\section{DISCUSSION}

In the present study, the Flesch reading ease test score and Flesch- Kincaid grade level test readability scores were 64 and 7.3 respectively. The Flesch reading ease test scores for the studies conducted by Adepu R et al and Roy RT et al was 80 and 69.9 respectively, which was better than our Flesch reading ease test readability score of PIL. ${ }^{5,6}$ The Flesch- Kincaid grade level test readability score was 7.1 in the study conducted by Roy RT et al, which is almost similar to our study. In the present study, the design and layout of the PILs was assessed using BALD criteria and the scores were 25 for English and Malayalam, and 26 for Kannada PILs. The scoring was fair with respect to the scoring done in PIL's made in similar studies conducted by Adepu R et al, Roy RT et al and Mateti UV et al.5,8, The BALD score of the PIL in the study by Adepu R et al was 22, Roy RT et al was 27 and Mateti UV et al was 28 (English) and 26 (Kannada). ${ }^{5,6,8}$

Our study results revealed that the occurrence of ACS was more predominant in male population than female population between the two groups. In the present study, most of the ACS patients were in the mean age group of above 57 years. These results were comparable with the studies conducted by Dias et al, Negi PC et al and Mohanan PP et $a l^{9-11}$ where the predominance of ACS was observed in male population than female population and the mean age of ACS occurrence was $59.16,60.9$ and 60.4 years of age respectively. The most common co-morbidities were hypertension (56.15\%) and diabetes (29.23\%) among ACS patients. These results were similar to the studies conducted by Negi PC et al and Mohanan PP et al, Azmi et al $l^{9,10,12}$ which reports as $43.4 \%, 48.4 \%$ and $61.5 \%$ of hypertension and $17.7 \%$, $37.6 \%$ and $29.8 \%$ of diabetes in the ACS population respectively.

In the present study, family history of patients did not have much role in the occurrence of ACS. Out of 130 patients, only $1.5 \%$ was seen in control group and none of the patients was seen in intervention group. This is concerning the study by Muniz et $a l^{13}$ where out of 


\begin{tabular}{|c|c|c|c|c|c|c|}
\hline \multirow{2}{*}{\multicolumn{2}{|c|}{ Demographic details }} & \multicolumn{2}{|c|}{$\begin{array}{l}\text { Control Group } \\
(n=65)\end{array}$} & \multicolumn{2}{|c|}{$\begin{array}{l}\text { Intervention Group } \\
(n=65)\end{array}$} & \multirow{3}{*}{$\begin{array}{c}\text { p value } \\
0.225 \text { (Fischer's Exact Test) }\end{array}$} \\
\hline & & \multirow{2}{*}{$\begin{array}{c}\text { Frequency } \\
-\end{array}$} & \multirow{2}{*}{$\begin{array}{c}\text { Percentage (\%) } \\
-\end{array}$} & \multirow{2}{*}{$\begin{array}{c}\text { Frequency } \\
2\end{array}$} & \multirow{2}{*}{$\begin{array}{c}\text { Percentage (\%) } \\
3.1\end{array}$} & \\
\hline \multirow{6}{*}{ Age groups } & $21-30$ & & & & & \\
\hline & $31-40$ & - & - & 1 & 1.5 & \\
\hline & $41-50$ & 16 & 24.6 & 16 & 24.6 & \\
\hline & $51-60$ & 20 & 30.8 & 16 & 24.6 & \\
\hline & $61-70$ & 18 & 27.7 & 25 & 38.5 & \\
\hline & $>70$ & 11 & 16.9 & 5 & 7.7 & \\
\hline \multicolumn{7}{|l|}{ Co-morbidities } \\
\hline Hypertension & & 40 & 61.5 & 33 & 50.8 & 0.289 (Chi- square Test) \\
\hline Diabetes Mellitus & & 13 & 20 & 25 & 38.5 & 0.033(Chi-square Test) \\
\hline Dyslipidemia & & 4 & 6.2 & 4 & 6.2 & 1.000(Fischer's Exact Test) \\
\hline Others & & 9 & 13.8 & 8 & 12.3 & 1.000(Chi-Square Test) \\
\hline \multicolumn{7}{|l|}{ Social habits } \\
\hline \multirow[t]{2}{*}{ Alcoholic } & Yes & 4 & 6.2 & 10 & 15.4 & \multirow[t]{2}{*}{ 0.374(Fischer's Exact Test) } \\
\hline & No & 61 & 93.8 & 55 & 84.6 & \\
\hline \multirow[t]{2}{*}{ Smoking } & Yes & 10 & 15.4 & 14 & 21.5 & \multirow[t]{2}{*}{ 0.155(Chi-Square Test) } \\
\hline & No & 55 & 84.6 & 50 & 76.9 & \\
\hline \multirow{2}{*}{$\begin{array}{l}\text { Family history } \\
\text { of ACS }\end{array}$} & Yes & 1 & 1.5 & - & - & \multirow[t]{2}{*}{ 1.000(Fischer's Exact Test) } \\
\hline & No & 64 & 98.5 & 65 & 100 & \\
\hline \multirow{5}{*}{$\begin{array}{l}\text { Number of } \\
\text { medications per } \\
\text { prescription }\end{array}$} & $1-2$ & 8 & 12.3 & 5 & 7.7 & \multirow[t]{5}{*}{ 0.693(Chi-Square Test) } \\
\hline & $3-4$ & 9 & 13.8 & 11 & 16.9 & \\
\hline & $5-6$ & 13 & 20 & 18 & 27.7 & \\
\hline & 7-8 & 26 & 40 & 21 & 32.3 & \\
\hline & $9-10$ & 9 & 13.8 & 10 & 15.4 & \\
\hline
\end{tabular}

Others - Chronic Obstructive Pulmonary Diseases (COPD), Upper Respiratory Tract Infection (URTI), Lower Respiratory Tract Infection (LRTI), Hypothyroidism, Goiter etc.

\begin{tabular}{|c|c|c|c|c|c|}
\hline \multirow[t]{2}{*}{ Symptoms } & \multicolumn{2}{|c|}{$\begin{array}{c}\text { Control group } \\
(n=65)\end{array}$} & \multicolumn{2}{|c|}{ Intervention group $(n=65)$} & \multirow[t]{2}{*}{$p$ value } \\
\hline & Frequency & Percentage (\%) & Frequency & Percentage (\%) & \\
\hline Chest pain & 52 & 80 & 53 & 81.5 & 1.000(Chi-Square Test) \\
\hline Palpitation & 4 & 6.2 & 4 & 6.2 & 1.000(Fischer's Exact Test) \\
\hline Dyspnea & 11 & 16.9 & 7 & 10.8 & 0.447 (Chi-Square Test) \\
\hline DOE & 26 & 40 & 27 & 41.5 & 1.000(Chi-Square Test) \\
\hline Diaphoresis & 3 & 4.6 & 8 & 12.3 & 0.206(Chi-Square Test) \\
\hline Giddiness & 5 & 7.7 & 1 & 1.5 & 0.208(Fischer's Exact Test) \\
\hline Cough & 3 & 4.6 & 3 & 4.6 & 1.000(Fischer's Exact Test) \\
\hline General Weakness & - & - & 6 & 9.2 & 0.028(Fischer's Exact Test) \\
\hline Others & 10 & 15.4 & 8 & 12.3 & 0.800 (Chi-Square Test) \\
\hline
\end{tabular}

Others-Vomiting, stomach discomfort, blurring vision; DOE-Dyspnea on Exertion 


\begin{tabular}{|c|c|c|c|}
\hline \multicolumn{4}{|c|}{ Table 3: Baseline QoL scores of ACS patients } \\
\hline \multirow{2}{*}{ Domains } & Control Group ( $\mathbf{n = 6 5 )}$ & Intervention Group (n=65) & \multirow{2}{*}{ p value } \\
\cline { 2 - 3 } & Mean \pm SD & Mean \pm SD & \\
\hline Physical & $55.50 \pm 14.97$ & $48.93 \pm 16.44$ & 0.060 \\
\hline Psychological & $59.48 \pm 16.84$ & $56.18 \pm 18.92$ & 0.565 \\
\hline Social relationships & $65.38 \pm 22.40$ & $55.36 \pm 23.31$ & 0.027 \\
\hline Environmental & $63.88 \pm 16.64$ & $61.00 \pm 19.69$ & 0.844 \\
\hline
\end{tabular}

Patient assessed for eligibility criteria $(\mathrm{n}=150)$

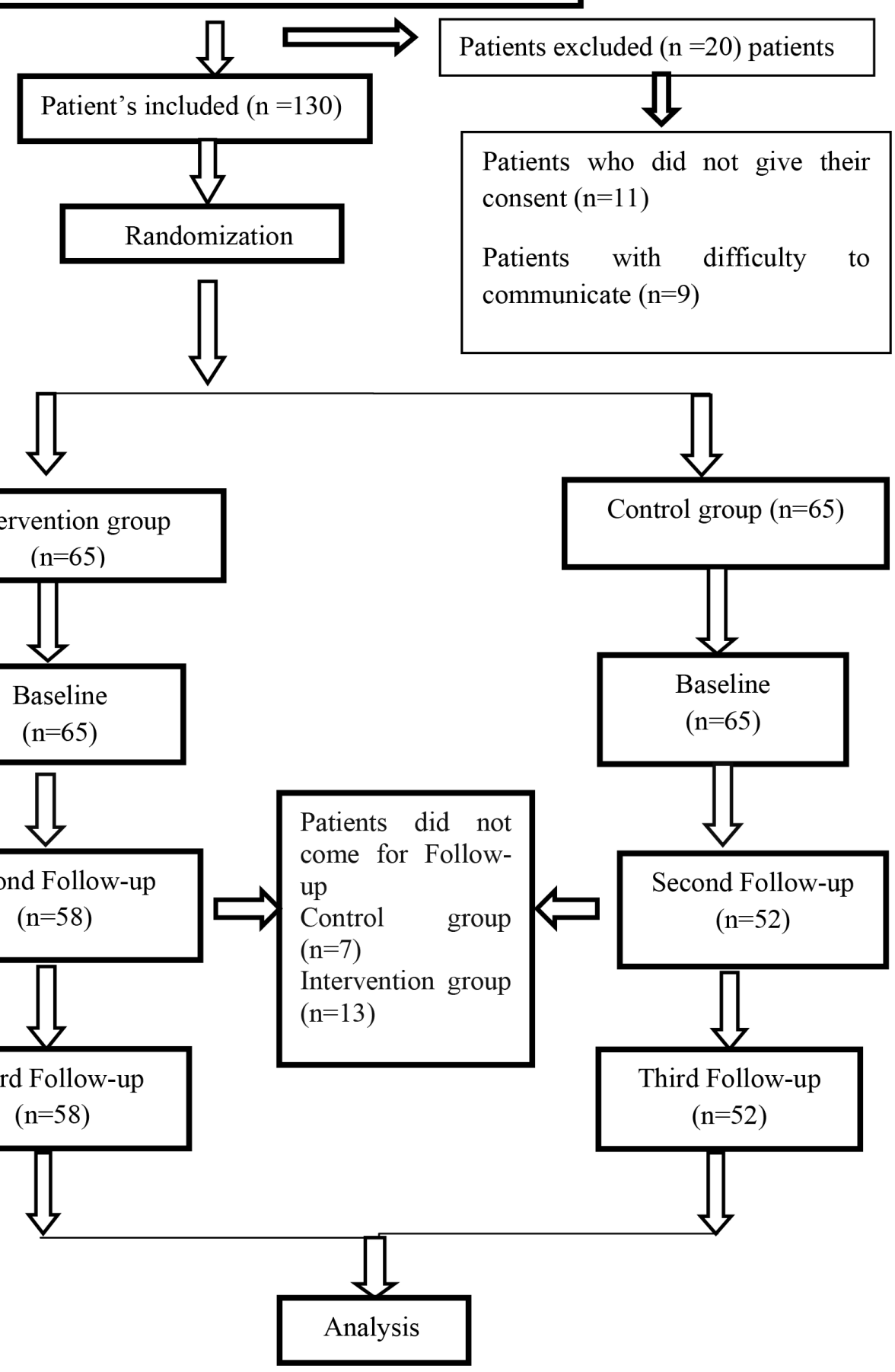

Figure 1: Methodology Flow-Chart. 


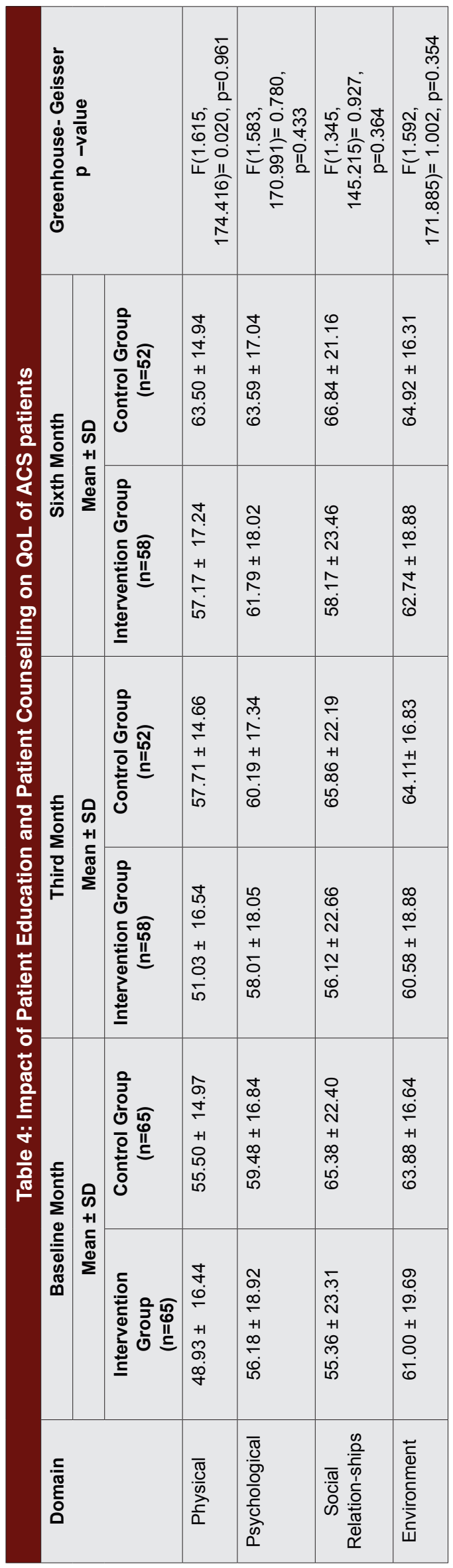

the 1,757 patients considered for the study, only $17 \%$ of prevalence was seen in control group while $18 \%$ of prevalence was seen in intervention group.

The present study shown that there is presence of risk factors likes smoking and alcoholism in ACS patients. Chow CK et al ${ }^{14}$ conducted a study to determine the influence the disease had on the lifestyle of the patients causing early cardiovascular events. It was found out that proper management of lifestyle events and having proper diet, exercise, smoking cessation caused a significant reduction in the cardiovascular events, and hence it should be imparted strictly along with treatment procedures.

In this study, prescriptions with anti-anxiety drugs were more indicating higher anxiety level among the patients. This was in favour of the study by Dias et al, ${ }^{9}$ which implies that there is higher level of anxiety among the patients considered for ACS studies. The reason for this may be the insecurity of the patient after the occurrence of the disease. The patients were anxious about their future, their family and due to the threat of death.

In the present study, there is no significant difference in the QoL scores of Physical, Psychological, Social Relationships and Environment domains between the two groups over a period. The QoL among ACS patients was reduced as correlated to healthy population as stated by the study conducted by Hasheni et al. ${ }^{15}$ The impact of patient counselling and Patient education in the QoL scores among diabetes by Adepu $\mathrm{R}$ et $\mathrm{al}^{16}$ and hypertensive patients by Biradar SS $e t$ al ${ }^{17}$ significantly improved in the intervention group compared to the control group over a period of 6 months. However, in the present study there is an improvement in the QoL scores of the intervention group compared to that of the control group. The survey of literature shown that there were no pharmacist interventions in the QoL of ACS patients. The significant change in QoL among ACS patients can only be seen after one year. In a comparative study conducted by Hasheni et al ${ }^{15}$ the results revealed that there was a reduced QoL after 3 months of QoL assessment in ACS patients.

The limitations for the present study is that the duration of study is very less and is not sufficient for the assessment of impact of Patient Education and Patient Counselling in QoL of ACS patients. Only small sample size was taken for the study and this sample size cannot outline the QoL of the total ACS patients. Use of generic instruments is a drawback as it is less sensitive to changes than that of specific instruments. The generic instrument was used in the study to have an insight to the overall QoL of ACS patients. In the pres- 
ent study, the clinical and economic outcomes were not evaluated due to time constrains and lack of funding sources.

\section{CONCLUSION}

In the present study, there is no significant difference in the QoL scores of Physical, Psychological, Social Relationships and Environment domains between the two groups over a period. However, in the present study there is an improvement in the QoL scores of the intervention group compared to that of the control group. A significant change in the QoL of the patients could be seen only if the study duration was for 12 months period. The outcome of the study highlights the need of care and cardiac rehabilitation programme for the improvement of the QoL of ACS patients. This care should be extended after discharge of patients from the hospital and maintained throughout their follow-up period. Provision of multi-disciplinary care will enable the improvement of QoL in ACS patients. In addition, lifestyle changes should be made by the patients themselves to have better cardiac output and close monitoring during the follow-up sessions can ensure this. Clinical Pharmacists service can be very beneficial for the management and monitoring of ACS patients to improve their QoL.

\section{ACKNOWLEDGEMENTS}

We would like to thank Dr. D.S. Puranik, former Head of the Department of Pharmacy Practice, NGSM Institute of Pharmaceutical Sciences (NGSMIPS) for his valuable suggestions and guidance. We would also like to express our sincere gratitude to Dr. C.S. Shastry, Principal, NGSMIPS, Nitte University, Mangalore for providing necessary facilities to carry out this research work.

\section{CONFLICT OF INTEREST}

The author have no conflict of interest.

\section{REFERENCES}

1. Amsterdam EA, Wenger NK, Brindis RG, Casey DE Jr, Ganiats TG, Holmes et al. 2014 AHA/ACC Guideline for the Management of Patients with Non-ST-Elevation Acute Coronary Syndromes: a report of the American College of Cardiology/American Heart Association Task Force on Practice Guidelines. J Am Coll Cardiol. 2014;64(24):e139-228. http://dx.doi. org/10.1016/j.jacc.2014.09.016; http://dx.doi.org/10.1016/j.jacc.2014.09.017; PMid:25260718

2. Medindia. Heart attack (internet). 2016. Available from http://www.medindia. net/patients/patients info/ Heart Attack.htm. [Last cited 4 March 2016].

3. Alves da Silva S, Passos SRL, Carballo MT, Figueiró M. Quality of Life Assessment after Acute Coronary Syndrome: Systematic Review. Arq Bras Cardiol. 2011;97:526-40.

4. Failde II, Soto MM. Changes in health related quality of life 3 months after an acute coronary syndrome. BMC Public Health. 2006;6(1):1-10. http://dx.doi. org/10.1186/1471-2458-6-1 ; PMid:16390547 PMCid:PMC1368965
5. Adepu R, Swamy MK. Development and evaluation of Patient information Leaflet Usefulness. IJPS. 2012;59:174-8. http://dx.doi.org/10.4103/0250474x.103857

6. Mateti UV, Nagappa AN, Attur RP, Bairy M, Nagaraja SP, Mallayasamy S et al. Preparation, Validation and user-testing of pictogram -based Patient Information Leaflet for hemodialysis patients. Saudi Pharmaceutical Journal. 2015;23(6):621-5. http://dx.doi.org/10.1016/j.jsps.2015.01.022; PMid:26702256 PMCid:PMC4669423.

7. Briffa T, Chow CK, Clark AM, Redfern J. Improving outcomes After Acute Coronary Syndrome with Rehabilitation and Secondary Prevention. Elsevier HS Journals. 2013;35(8):1076-1081. http://dx.doi.org/10.1016/j. clinthera.2013.07.426.

8. Roy RT, Sekhar MS, Rodrigues GS, R V et al. Preparation and readability assessment of Patient Information Leaflet for diabetic foot ulcers. Journal of Social Health and Diabetes. 2013;1(2):79-81. http://dx.doi.org/10.4103/23210656.115304.

9. Dias CM, Macedo LB, Gomes LT, de Oliveira PL, Albuquerque IV, Lemos AQ et al. Quality of life of patients after an acute coronary event. J Clin Med Res. 2014;6(5):362-8. PMid:25110540 PMCid:PMC4125331.

10. Negi PC, Merwaha R, Panday D, Chauhan V, Guleri R. Multicenter HP ACS Registry. Indian Heart J. 2016;68:118-27. http://dx.doi.org/10.1016/j. ihj.2015.07.027; PMid:27133317.

11. Mohanan PP, Mathew R, Harikrishnan S, Krishnan MN, Zachariah G, Joseph J, et al. Presentation, management, and outcomes of 25748 acute coronary syndrome admissions in Kerala, India: results from the Kerala ACS Registry. Eur Heart J. 2013;34(2):121-9. http://dx.doi.org/10.1093/eurheartj/ehs219; PMid:22961945 PMCid:PMC3538274.

12. Azmi S, Goh A, Fon A, Anchah L. Quality of life among Patients with Acute Coronary Syndrome in Malaysia. Value In Health Regional Issues. 2015;6c:80 -83. http://dx.doi.org/10.1016/j.vhri.2015.03.015.

13. Muniz J, Doblas G, Perez S, Goya L, Eizagetexiberria M, Galvain T et al. The Effect of post-discharge educational intervention on patients in achieving Objectives in modifiable risk factors six months after discharge following an Episode of ACS: a randomized control trial. Health and quality of life outcomes. 2010;8(1):1-16.

14. Chow KC, Jolly S, Melacini P, Fox AA, Anand SS, Yusuf. Association Of diet, Exercise, and modification with risk of early cardiovascular events after ACS. Circulation. 2010;121(6):750-8. http://dx.doi.org/10.1161/ CIRCULATIONAHA.109.891523; PMid:20124123.

15. Hasheni BV, Somasiri KG. Quality of life after ACS; a comparative study. Galle Medical Journal. 2012;17:12-8. http://dx.doi.org/10.4038/gmj. v17i2.4917.

16. Adepu R, Rasheed A, Nagavi BG. Effect of patient counseling on quality of life in typ-2 diabetes mellitus patients in two selected South Indian community pharmacies: A study. 2007;69(4):519-24.

17. Biradar SS, Kapate R, Srinivas R and Raju SA. Assessment of Pharmacist mediated Patient Counseling on Hypertensive Compliance with Quality of Life in South Indian City. International Research Journal of Pharmacy. 2012;3(6):206-9.

\section{SUMMARY}

- The patients were randomized into intervention and control groups in 1:1 ratio by chit method.

- Customized pharmacist counselling and education was provided to acute coronary syndrome patients.

- The counselling includes the information about the disease, treatment goals, and importance of medication adherence, possible adverse drug reactions, management of the disease and life style modifications.

- The PIL was developed by referring to the various primary, secondary and tertiary resources.

- The QoL of patients was assessed by WHOQOLBREF questionnaire at baseline, third month and sixth month of the study.

- There was an improvement in the QoL scores in the ACS patients in the intervention group compared to control group but not statistically significant. 